\title{
La defensa de la competencia en la Constitución Argentina
}

Marcela Basterra

\section{Mercado y defensa de la competencia en la Constitución nacional}

La idea de un «sistema» fundado en la propiedad privada y en el mercado es lo que se conoce como sistema liberal o de economía de mercado y que fuera identificado por Duverger ${ }^{1}$ como el correlato lógico con el sistema democrático, de forma tal que el uno en lo económico, y el otro en lo político, se fundamenten en la libertad; idea a la cual adscribieron los primeros constituyentes.

La constitución argentina $1853 / 60$ no contenía definiciones en materia económica sobre la adopción del sistema de economía de mercado. El mismo surge de la interpretación de algunas de sus disposiciones, más aún si hacemos una interpretación "originalista», surge claramente en la obra Sistema económico y rentístico de la Confederación argentina de quien fuera el principal mentor de la Constitución nacional Juan Bautista Alberdi² ${ }^{2}$ quien en su otra gran obra Bases sostuvo que si se liberaban las trabas a la actividad económica, florecerían las industrias, las ciencias y las artes. Pero debía para ello consolidarse un gran espacio e incrementar la población. No deben existir trabas a la libre circulación de los bienes en el territorio de la Confederación.

1 Maurice Duverger, Instituciones Políticas y Derecho Constitucional, Ariel, Barcelona, Citado por Alberto Dalla Vía en «El mercado en la Constitución», ED, 17 de agosto de 1999.

2 Juan Bautista Alberdi. Bases, Colección Esquemas Políticos, Editorial Plus Ultra, Buenos Aires, 1981. 
La conformación de un solo mercado desde el punto de vista económico tiene su base en la Constitución de los Estados Unidos; la adopción de un modelo de libre circulación interior de personas, bienes y mercaderías; el reconocimiento único de las aduanas nacionales trajo aparejado la eliminación de las "barreras interiores"; características del proteccionismo colonial. El país se constituyó como una unidad económica, más allá de las distintas economías regionales.

La Constitución cumple una función integradora, que también se proyecta sobre el ámbito económico. El principio de unidad económica, es una resultante de la constitución, y no jurídicamente algo anterior a ella. La inclusión de normas en la constitución dirigidas a regular las conductas económicas de los agentes que participan de dicha actividad, hacen aparecer esta función de integración, especialmente perceptible: por cuanto la constitución contiene reglas sobre el orden y el proceso económico, y en tanto que ella es única y vincula a todos por igual; establece un marco jurídico unitario para la disciplina de la actividad económica. ${ }^{3}$

Esta interpretación resulta necesaria si partimos de la base que la competencia está insertada en un contexto normativo al que se deberán ajustar los agentes económicos, siendo la Constitución nacional y los valores por ella sustentados la norma fundamental de dicho ordenamiento a la que deberán ajustarse las demás normas.

En los artículos $9^{\circ}, 10^{\circ}, 11^{\circ}$ y $12^{\circ}$ la norma constitucional ha procurado la conformación de un solo espacio económico sentando el principio de libertad de circulación interior y el de la eliminación de las aduanas interiores, estableciendo que existen solo «aduanas exteriores», conforme surge del artículo $10^{\circ}$. El artículo $14^{\circ}$ consagra entre los "derechos que gozan los habitantes de la nación [...]; el de trabajar y ejercer toda industria lícita; de navegar y comerciar, de transitar por el territorio argentino". También es parte de este contexto el artículo $19^{\circ}$ in fine al establecer que "Ningún habitante de la nación será obligado a hacer lo que no manda la ley, ni privado de lo que ella no prohiben; este conocido principio de legalidad, es también susceptible de ser aplicado a los derechos económicos. El artículo $20^{\circ}$ prevé estos dere-

3 Alberto R. Dalla Vía. Derecho Constitucional Económico, Capítulo X «El Mercado como Sistema Constitucional de Intercambio de Recursos", Editorial Abeledo Perrot, Buenos Aires, septiembre de 1999, p. 393 y ss. 
chos para los extranjeros, como para asegurárselos en caso de no quedar suficientemente claro al ser enunciados para los «habitantes» en el artículo $14^{\circ}$. En la norma del artículo $26^{\circ}$ se establece la libre navegación de los ríos interiores.

Con la reforma Constitucional de 1994; este principio se vigoriza y actualiza en determinadas normas como el artículo $41^{4}$ que establece la regulación federal del medio ambiente en cuanto a los denominados "presupuestos mínimos"; el artículo $42^{5}$ en cuanto hace referencia al modelo de competencia y al de protección de usuarios y consumidores, con una redacción en la cual es notoria que alude a la economía de mercado; el artículo $43^{6}$ en lo que se refiere a la acción de amparo

4 Artículo $41^{\circ}$.- Todos los habitantes gozan del derecho a un ambiente sano, equilibrado, apto para el desarrollo humano y para que las actividades productivas satisfagan las necesidades presentes sin comprometer las de las generaciones futuras; y tienen el deber de preservarlo. El daño ambiental generará prioritariamente la obligación de recomponer, según lo establezca la ley. Las autoridades proveerán a la protección de este derecho, a la utilización racional de los recursos naturales, a la preservación del patrimonio natural y cultural y de la diversidad biológica, y a la información y educación ambientales. Corresponde a la Nación dictar las normas que contengan los presupuestos mínimos de protección, y a las provincias, las necesarias para complementarlas, sin que aquéllas alteren las jurisdicciones locales. Se prohibe el ingreso al territorio nacional de residuos actual o potencialmente peligrosos, y de los radiactivos.

5 Artículo $42^{\circ}$.- Los consumidores y usuarios de bienes y servicios tienen derecho, en la relación de consumo, a la protección de su salud, seguridad e intereses económicos; a una información adecuada y veraz; a la libertad de elección y a condiciones de trato equitativo y digno. Las autoridades proveerán a la protección de esos derechos, a la educación para el consumo, a la defensa de la competencia contra toda forma de distorsión de los mercados, al control de los monopolios naturales y legales, al de la calidad y eficiencia de los servicios públicos, y a la constitución de asociaciones de consumidores y de usuarios. La legislación establecerá procedimientos eficaces para la prevención y solución de conflictos, y los marcos regulatorios de los servicios públicos de competencia nacional, previendo la necesaria participación de las asociaciones de consumidores y usuarios y de las provincias interesadas, en los organismos de control.

6 Artículo $43^{\circ}$.- Toda persona podrá interponer acción rápida y expedita de amparo [...]. Podrán interponer esta acción contra cualquier forma de discriminación y en lo relativo a los derechos que protegen al ambiente, a la competencia, al usuario y al consumidor, así como a los derechos de incidencia colectiva en general, el afectado, el defensor del pueblo y las asociaciones que propendan a esos fines, registradas conforme a la ley, la que determinará los requisitos y formas de su organización. 
extendiendo la protección de la misma a los derechos que protegen la competencia.

El artículo $75^{\circ}$ entre las atribuciones del Congreso contiene determinadas cláusulas que son acordes con esta interpretación; así los incisos 1 y 2 al ratificar la competencia del Congreso de la nación para legislar en materia aduanera y fiscal; del inciso 13 surge la denominada "cláusula comercial»; del inciso 18 la denominada "cláusula del progreso" y del inciso 19 la "cláusula del nuevo progreso; o del progreso económico con justicia social».

Alberto Dalla Vía, siguiendo a Julio Olivera ${ }^{7}$ nos dice que del conjunto de todas estas normas enunciadas desde la constitución originaria hasta la última reforma, surge con claridad que la intención del constituyente ha sido la de diseñar un solo mercado en el territorio de la nación. Se trata del «principio constitucional de la integración económica».

Estas normas guardan una estrecha relación entre sí y se enlazan en forma coherente con otras que conforme al principio de unidad de interpretación; y dentro de un sistema de normas como es la Constitución nacional permite inferir los valores inherentes a ella.

La competencia está especialmente protegida en los artículos $42^{\circ}$ y $43^{\circ}$, ambos incorporados en 1994 en el capítulo segundo "Nuevos Derechos y Garantías».

Cionfrini ${ }^{8}$ entiende que la Constitución coloca a las diversas formas de mercado como garantía de satisfacción del bienestar general; según el autor explica, en los artículos $42^{\circ}$ y $43^{\circ}$ de la Carta Magna se establece una relación jurídica de al menos dos dimensiones entre los derechos, obligaciones y garantías que hacen al consumo y a la competencia: una dimensión individual (derechos y obligaciones individuales); de reconocer el derecho a adecuadas condiciones de satisfacción de deseos y necesidades, tanto individuales como familiares; pero relacionados con un interés personal; y una dimensión pública (derechos y obligaciones de incidencia colectiva); de aumento o disminución de la calidad de vida y del bienestar general, derivada de la acción de

7 Julio H. G. Olivera, El Modelo Constitucional de la Integración Económica. Academia Nacional de Derecho y Ciencias Sociales de Buenos Aires. Anticipo Anales Año XXXIII segunda época. No 26.

8 Ernesto Cionfrini. La protección de los mercados y la competencia en la Constitución Nacional: L.L, «Doctrina Judicial», 31 de mayo de 2000, pp. 308-309. 
múltiples acciones individuales o familiares y la incidencia colectiva que tienen los derechos relacionados con el consumo y la competencia.

En el artículo $42^{\circ}$ queda establecido expresamente el deber por parte del Estado de «defender la competencia contra toda forma de distorsión de los mercados y control de los monopolios naturales o legales». Estas disposiciones son perfectamente armónicas dentro del ámbito de libertad económica y de libre iniciativa privada que asegura nuestra constitución; porque estos derechos reconocidos en la presente norma no escapan al principio general que es aplicable a todos los derechos plasmados en la constitución; y es que el ejercicio de los derechos puede ser «razonablemente» reglamentado; conforme surge del juego de los artículos $14^{\circ}$ y $28^{\circ}$ de la constitución nacional.

El ámbito de libertad de comercio, de iniciativa, de industria, de competir, etc. es regulado por la constitución y por el conjunto de leyes, decretos y normas jurídicas; o sea que el ejercicio de los derechos de libertad económica puede ser reglamentado, y dicha reglamentación debe lograr que el ejercicio de los derechos de unos no menoscabe el ejercicio de los derechos de otros.

La importancia que se ha dado aquí al ordenamiento jurídico, haciendo abstracción del mayor o menor grado de cumplimiento por parte de los particulares o del Estado, está dada en que es éste el que determina los grados de libertad y de competencia en los mercados: si la legislación establece fuertes regulaciones o requisitos para la instalación de comercios o de industrias - "barreras a la entrada»-, o se estipulan controles sobre los precios -precios máximos-, o sobre las cantidades o lugares de producción -cupos, distribución del mercado por regiones-, los grados de libertad económica y de competencia en un mercado ser verán disminuidos, tal como ocurrió durante algunos períodos en nuestro país.

Asimismo, si el sistema impositivo o de otorgamiento de subsidios, beneficios o promociones coloca a algunos agentes en situación de ventaja con respecto a otros con quienes va a competir, el punto de partida no será el de una estricta igualdad formal entre agentes económicos sino el de posiciones fácticas y jurídicas diferentes. No nos olvidemos que el Congreso por atribuciones otorgadas en el artículo $75^{\circ}$ inciso 18 "cláusula del progreso", puede sancionar "leyes protectoras [...] otorgar concesiones temporales de privilegio y recompensas de estímulo"; y por el inciso 19 "cláusula del nuevo progreso"; debe "pro- 
veer al progreso económico con justicia social, a la productividad de la economía nacional [...]; promover políticas diferenciadas que tiendan a equilibrar el desigual desarrollo relativo de provincias y regiones».

Estas consideraciones tienen como finalidad entender a la competencia como un proceso económico regulado por el derecho, que no debe concebirse en abstracto, que puede ser distinto en los diferentes sectores de la economía, y que no está sujeta a reglas o parámetros uniformes e invariables; antes bien es un proceso dinámico -en lo fáctico y en lo jurídico- cuyos límites grados y alcances pueden ser generales o estar determinados para cada sector económico, tanto por las reglas jurídicas que rigen en él como por la actividad que desarrollan las autoridades públicas en cada caso determinado ${ }^{9}$.

El artículo $42^{\circ}$ de la constitución nacional plantea la necesidad por parte del Estado del ejercicio de un control en la defensa de la competencia, evitando los monopolios naturales y legales. Entendemos por monopolio a aquella situación que se verifica en el mercado cuando por la actuación preponderante de un operador del mismo, por decisión de la autoridad, la competencia se encuentra suprimida o acotada, de tal forma que determina condiciones rígidas en la oferta de bienes y servicios. Pudiendo ser los mismos naturales o legales - conceptos que ya mencionáramos- según la norma constitucional de 1994.

Quizá aquí visualizamos con claridad la sustitución de un Estado protector por un Estado regulador, pero dicha regulación no debe estar orientada a sustituir al mercado y a la competencia; sino más bien a promoverlos. Es necesario por tanto que todos los procesos de privatizaciones importantes vayan acompañados de un marco regulador de la actividad privatizada. Importantes juristas como Forsthoff en Alemania y Pound en el mundo anglosajón, se preocuparon ante la posibilidad de potenciación del poder del Estado como consecuencia de la demanda de prestaciones en previsión existencial, y el peligro que ello puede importar en relación a la libertad individual.

Daniel Bell ${ }^{10}$ al calificar a nuestra sociedad como "The Communal Society" la caracteriza en tres principios: a) El aumento en alcance y

9 Ernesto Cionfrini. Op. cit. p. 120.

10 Alberto R. Dalla Vía. «El Rol del Estado en la Defensa de la Competencia», En Leyes Reglamentarias de la Reforma Constitucional, Asociación Argentina de Derecho Constitucional, Buenos Aires, 1996, pp. 162-163. 
número de los "bienes públicos", comprados por el gobierno con carácter general para todo el pueblo; b) la extensión de las "externalidades"; la necesidad de controlar internalizando en lo posible, dichos costos, ha originado una considerable extensión a los poderes gubernamentales; c) el reconocimiento de una igualdad radical de las personas y el derecho de cada una de ellas a un "mínimo vital»; - trabajo, protección contra el desempleo, salud, educación, vivienda digna, jubilación -; esos derechos sociales y económicos que están reconocidos con mayor o menor alcance en todas las constituciones modernas. El reflejo de esta «Communal Society» sobre el Estado es, según el autor, claro: mayor control público, mayor regulación y un Estado de prestaciones a través del cual se desea obtener una redistribución de los resultados del proceso económico. En la mayoría de los países, la legislación ha separado un conjunto de actividades que con el nombre de servicios públicos, actividades reglamentadas, actividades de interés general o nombres parecidos, se hallan "disciplinadas» y sometidas al poder público, sujetas a regulaciones.

Todas las sociedades tienen determinadas actividades públicas, que si bien varían en los distintos países y en distintas épocas en general son comunes tales como los servicios de transportes, comunicaciones telefónicas, medios de comunicación - radio, televisión -, servicios de electricidad, abastecimiento de agua, gas, actividades relacionadas con la urbanización - viviendas -, actividades asistenciales, de sanidad, bancarias, crediticias, etc. Estas actividades o las empresas que las brindan necesitaran de una regulación con miras a establecer las relaciones entre ellas y el Estado.

Por otra parte entre dichas empresas puede darse una competencia lógica y leal; o bien que alguna de ellas ostente una posición dominante en el mercado erigiéndose en monopólica. La ley para cumplir con la máxima constitucional pensamos que debe distinguir el control que se deberá realizar en aquellas actividades que se ejercen monopólicamente de aquellos servicios realizados en condiciones de competencia; puesto que en este último caso rigen los principios de libertad de contratar, libertad de ingreso de nuevos prestadores y servicios substitutivos, asimismo como la libertad en los precios y tarifas. Siendo de esta manera, el Estado solo deberá limitarse a realizar el control respectivo sobre la salubridad, la seguridad, la preservación del ambiente, que se respeten los derechos de usuarios y consumidores y se cumplan las normas de 
lealtad comercial. En cambio cuando una de dichas actividades se brinda en forma de monopolio es necesario que el Estado amplíe la esfera de control hacia los caracteres de la prestación, la calidad y sobre todo si se trata de precios justos.

La norma del artículo $42^{\circ}$ de la Constitución Nacional es clara y prevé expresamente la obligación del Estado de defensa de la competencia contra cualquier forma de distorsión del mercado y del control de los monopolios. En definitiva se trata de asegurar un mercado transparente, en el que el consumidor pueda tener variedad de opciones, y de lograr que el Estado cumpla con esta obligación sancionando leyes que contengan reglas de juego claras y definidas. Eludir esta responsabilidad sería tanto como aceptar que la competitividad entre empresas en un combate sin reglas, lo que traerá aparejado un grave perjuicio para el interés general.

La nueva Ley antimonopolios $N^{\circ} 25.156$ del 25 de agosto de 1999 es, sin duda una ley reglamentaria del derecho constitucional plasmado en dicha norma. La que por otra parte ha sido acogida por la jurisprudencia tanto federal como local dando amplitud a su alcance; a modo de ejemplo en un reciente fallo del Tribunal Superior de Neuquén "Othaz Miguel A. C/ Municipalidad del Neuquén»-sentencia del 30 de junio de 1998- se establece que: «El principio de concurrencia que integran los principios inherentes a la defensa de la competencia del artículo $42^{\circ}$ de la Constitución Nacional, resulta plenamente aplicable a las relaciones entre los particulares y el Estado en el ámbito de la contratación administrativa. Así la alusión del procedimiento de licitación pública (cuando la concurrencia es posible) constituye una forma de distorsionar el mercado"."

Esta norma se complementa con el artículo $43^{\circ}$ en el que se contempla la acción de amparo colectivo, para el caso en que alguien se considere "afectado" en este derecho pueda hacerlo valer ante los tribunales, ya sea por sí mismo, por medio de una asociación que propenda a esos fines o a través del defensor del pueblo.

Según José Eugenio Soriano García ${ }^{12}$ la tesis que minusvalora la defensa de la competencia como elemento fundamental de las potesta-

11 La Ley. Doctrina Judicial, 1999-1, p. 227.

12 José Eugenio Soriano García, Derecho Público de la Competencia -Monografías Jurídicas- IDELCO, Madrid, España, 1998, pp. 62-64. 
des del Estado coincide necesariamente con la tesis que considera que el Estado no es una institución y que, consecuentemente la libertad de empresa no es un derecho fundamental en el que aquella se refleja individualmente. Los que consideran al mercado obra del azar con base en el albedrío de los operadores económicos, lo que sería equivalente a una "selva económica", prevaleciendo la ley del más fuerte o el más predador, rechazan la competencia condenándola precisamente por considerarla causal del salvajismo mercantil. Por lo tanto, rechazan la utilización de la acción de los poderes públicos para la implantación, fijación y exigencia de las leyes de defensa de la competencia.

La defensa de la competencia sin embargo, es uno de los principios guía de la actuación del Estado; «el mercado es una institución, como tal solamente generable allí donde existen poderes estatales consolidados que tienen como función, justamente, preservar el mercado, el orden público económico y fijar límites a la libertad de empresa [...] $\|^{13}$.

Consideramos que la defensa de la competencia es un instrumento clave para el buen funcionamiento del mercado; así lo entendieron nuestros constituyentes, y así afortunadamente parece ser un tema del que van tomando conciencia los juristas. Rompiendo de esta manera, a través de la legislación de esta materia en gran cantidad de países del mundo, con una tradición monopolista de siglos.

Hay una nueva cultura que exige que el Estado haciendo uso de su poder administrador, vigile el comportamiento de los agentes económicos para lograr que éstos compitan entre sí, con miras a ofrecer a los ciudadanos mejores precios, calidad y servicios; al mismo tiempo que se promueve la innovación tecnológica. Sin embargo, para hacerse con el mercado no se trata de aplicar la ley del "todo vale», hay que competir de manera «leal», respetando ciertos límites. Ésta es precisamente la razón de ser de un régimen de defensa de la competencia, que pensamos que en el contexto actual además deberá proyectarse en el plano regional; en nuestro caso en el Mercosur.

La defensa del mercado como genuina institución con lugar propio en un Estado de Derecho es precisamente el fin principal del Derecho público de la defensa de la competencia. 


\section{Privatización y desregulación del mercado}

A pesar de los enunciados de nuestra Constitución, existía una clara contradicción entre los valores explícitos en ella y las políticas concretas que se llevaban a cabo en el país de corte netamente intervencionista. Empresas estatales monopólicas, generalmente prestadoras de servicios públicos esenciales y políticas intervencionistas parecen desmentir la letra y el espíritu de nuestra Carta fundamental.

En la legislación argentina en materia de defensa de la competencia encontramos algunas normas aisladas desde 1919; en 1923 la legislación antimonopólica tuvo su primera manifestación con la sanción de la Ley $\mathrm{N}^{0}$ 11.210. Desde entonces esta fue varias veces modificada, siempre con la nota común de asignar crecientes responsabilidades al poder ejecutivo en la esperanza de obtener una mayor efectividad en su aplicación. Pero es recién a partir de las dos últimas décadas que contamos con una legislación destinada a reprimir las conductas que puedan afectar, limitar o distorsionar la competencia de los mercados y asegurar su buen funcionamiento. Nos referimos específicamente a la Ley $\mathrm{N}^{\circ} 22.262$ promulgada en agosto de 1980; y a la Ley $\mathrm{N}^{\circ} 25.156$ del 25 de agosto de 1999.

La importancia que se ha comenzado a dar al tema en nuestro país, se advierte también en los demás países de la región; esto se debe a distintos factores de diverso orden -fáctico, valorativo, jurídico, político, etc.- que marcan esta tendencia común: a) la gran cantidad de empresas del Estado, en su mayoría en forma monopólica, y la política de privatizaciones en reemplazo de los gestores estatales; b) la generalización de políticas de desregulación de los mercados, con la consiguiente eliminación de barreras al ingreso y un aumento sustancial de la competencia; c) la creciente liberalización del comercio internacional, y el ingreso en los mercados internacionales de países, regiones o bloques económicos; que genera a los Estados compromisos en materia de liberalización de mercados, a través de acuerdos internacionales o multinacionales; d) la configuración de bloques económicos o sistemas regionales de integración económica que obliga a los Estados a garantizar la competencia entre los agentes económicos de diferentes países; e) la apertura a nuevas tecnologías, con el consiguiente ingreso de empresas o capitales, que genera entre otras cosas, la necesidad de modificación del marco jurídico que regulan los mercados. ${ }^{14}$ 
Es indudable que el tema de la libre competencia se actualiza con motivo de la Ley de reforma $\mathrm{N}^{\circ} 23.696$ y la desregulación económica; por Decreto $\mathrm{N}^{\circ} 2284 / 91$. Por la primera se posibilitó que al pasar a la gestión privada, la actividad económica que realizaban las empresas públicas comenzara a ser regida sobre la base de los principios de la economía de mercado.

La desregulación a su vez, trata de eliminar determinados instrumentos que distorsionaban la competencia, dejando sin efecto «las restricciones a la oferta de bienes y servicios en todo el territorio nacional [...] y todas las otras restricciones que distorsionen los precios del mercado evitando la interacción espontánea de la oferta y la demanda», aunque exceptúa a las actividades vinculadas con la defensa nacional, la seguridad interior, la prestación de servicios públicos que constituyan monopolios naturales o legales, regulados por leyes específicas, (artículo $1^{\circ}$ Decreto $\mathrm{N}^{\circ} 2284 / 91$ ).

Esta apertura modifica las relaciones entre el mercado y sus agentes; porque en épocas de economía "cerrada"; el Estado sustituye al mercado. Actualmente, con una economía «abierta», el Estado tiene el deber de garantizar el funcionamiento del mercado; tal como surge claramente del artículo $42^{\circ}$ de la constitución nacional.

En este contexto, el proceso de privatización y de desregulación implica la recuperación del riesgo empresario, el derecho a la iniciativa privada y el estímulo a la inversión. La iniciativa privada, la participación comprometida del capital privado, bajo la dirección general del Estado, genera la competencia y limita el monopolio. ${ }^{15}$

\section{La Ley de Defensa de la Competencia $N^{\circ} 25.156$ y los monopolios}

\subsection{Antecedentes nacionales y extranjeros}

El antecedente inmediato en nuestro país, es la Ley $\mathrm{N}^{\circ} 22.262$ sancionada en 1980, y desde entonces ha sido aplicada hasta la promulgación

14 Ernesto Cionfrini. Curso de posgrado sobre "Defensa de la Competencia». UBA. $1^{\circ}$ Cuatrimestre 1999.

15 Roberto Dromi. Competencia y Monopolio, Argentina, Mercosur y OMC, Ciudad Argentina, Buenos Aires, 1999, pp.14-16. 
de la reciente ley de agosto de 1999; tanto por la Comisión Nacional de defensa de la competencia, por tribunales federales y del fuero penal económico, para los casos de denuncias por prácticas que interfieren en el funcionamiento competitivo de los mercados.

El propósito básico de esta norma legal fue evitar las prácticas anticompetitivas que puedan afectar el bienestar general de la comunidad. En consecuencia, tal como surge de los documentos de la $\mathrm{CNDC}^{16}$; la ley tuvo por objeto las conductas y no las estructuras de los mercados; pero en relación a las consecuencias y no a las causas que generan dichas conductas.

De la misma exposición de motivos surge que esta ley tenía tres objetivos fundamentales; a) definir con mayor precisión las conductas reprimidas, para limitar, restringir o distorsionar la competencia, b) instrumentar un procedimiento administrativo, orientado a la investigación de conductas y c) elaborar el marco jurídico adecuado, para asegurar de modo cabal, el correcto funcionamiento de los mercados, o por lo menos, tiende a constituirse en un arma eficaz para garantizar la transparencia, el normal desarrollo de un mercado, con el consiguiente bienestar general para consumidores y usuarios.

La ley tiende a regularizar la situación de los mercados nacionales, y que se cuente con un ordenamiento que ponga en manos del Estado normas penales que le habiliten para adoptar la correspondiente actitud coactiva frente a quienes limiten el funcionamiento del mercado.

En relación a los "Monopolios»" ${ }^{17}$ la parte sustancial de esta ley establece en primer lugar, los objetivos de la misma; el artículo $1^{\circ}$ dice: «Están prohibidos y serán sancionados de conformidad con las normas de la presente ley los actos o conductas relacionados con la producción o intercambio de bienes o servicios, que limiten, restrinjan o distorsionen la competencia o que constituyan abuso de una posición dominante del mercado, de modo que pueda resultar perjuicio para el interés económico general». La ley sanciona, por un lado el abuso de posición dominante, y por otro las restricciones, limitaciones o distorsiones a la

16 Comisión Nacional de Defensa de la Competencia; Memoria Anual 1997. p. 13.

17 Marcela Ampliar de Basterra. "La Defensa de la Competencia. Las Leyes Antimonopolio y la Constitución Nacional»; Revista Científica (UCES), Volumen IV. $N^{\circ}$ 1. Otoño de 2000. (Trabajo realizado antes de la sanción de la Ley No 25.156). 
libre concurrencia. Estas conductas aparecen como alternativas, puede darse el primer o el segundo caso, pero el "perjuicio al interés económico general» es una condición necesaria para que se configure una violación a la ley; lo que implica que para que una conducta sea sancionable a través de la presente ley debería, por un lado ser anticompetitiva - distorsión del mercado o abuso de una posición dominante -; y por el otro ser perjudicial para la comunidad.

Se incluye la figura de "posición dominante", prevista en otras legislaciones contemporáneas, que tiene en cuenta que determinadas conductas anticompetitivas pueden ser consecuencia de decisiones unilaterales fundamentadas en la posición adquirida en un mercado determinado.

Tal situación se presenta en los llamados «monopolios naturales»; que serán aquellos en los cuales dadas las condiciones que deberán hacerse la provisión de bienes y servicios no resulta posible la concurrencia de otros prestadores en competencia. Es una situación típica que es habitual por ejemplo en la prestación de servicios domiciliarios como de saneamiento en los que, dada la complejidad técnica de las instalaciones no permite la concurrencia de más de un prestador en una determinada área. Estos no son punibles en sí mismos, pero pueden originar abusos sancionables. También puede darse el caso de «monopolios legales» en los cuales no se presentan los inconvenientes técnicos anteriores, son establecidos por el Estado, muchas veces fundamentándolos en economía de escala. ${ }^{18}$

Es notable que la norma de marras requería que las conductas sean de naturaleza económica y que puedan resultar perjudiciales para el interés económico general. Con la potencialidad de un perjuicio se hace referencia a un peligro concreto razonablemente a determinarse en cada caso particular y no a una simple posibilidad lógica o abstracta de lesión; y con la afectación del interés económico general se dejan a salvo las conductas que puedan aparecer anticompetitivas pero en verdad resulta beneficiosa para la comunidad. ${ }^{19}$

18 Roberto Dromi y Eduardo Menem. La Constitución Reformada, comentada, interpretada y concordada; Ediciones Ciudad de Buenos Aires, Buenos Aires, 1994.

19 Ley $\mathrm{N}^{\circ} 22.262$ de Defensa de la Competencia, Comisión Nacional de Defensa de la Competencia, p.3. 
No es la existencia de hecho de una posición dominante de un mercado, ni el comportamiento normal de una actividad comercial o empresarial tendiente a ganar mercado, sino que son las distorsiones artificiales, las maniobras dolosas, el ejercicio irrazonable del poder económico, lo que pretende sancionar esta ley, son las conductas «anormales» que llevan al monopolio. La condición monopólica en sí misma representa una composición estructural del mercado, una posición que puede implicar el peligro de que la empresa monopólica ceda a la tentación de imponer condiciones abusivas.

No son pocos los autores que han venido predicando los efectos nocivos de los monopolios, entre ellos están los de la «escuela de Harvard», como Areeda; los de la escuela de Nueva York como Barry Hawk y Eleanor Fox, casualmente los más consultados por la Unión Europea; y los de la «escuela de Chicago" como Bork, Porter y Richard Posner; este es el "núcleo duro" de la competencia. "The american antitrust revolution ${ }^{20}$ Richard Posner explica que en relación a las consecuencias del monopolio para la eficiencia hay que tener en cuenta que la producción es menor en el monopolio que en la competencia. El autor lo fundamenta en que el precio del monopolio hace que algunos consumidores cambien a otros productos, que se vuelven más atractivos por el aumento del precio monopólico. En esta sustitución hay una pérdida de valor. Esto se ve claramente si suponemos que para cada uso del producto monopolizado hay un producto sustituto idéntico de precio menor. El monopolio, entonces hace que algunos consumidores satisfagan sus demandas con otros bienes cuya producción es más cara que el bien monopolizado. El costo adicional constituye un desperdicio para la sociedad. ${ }^{21}$

La libre competencia se relaciona estrechamente con el concepto de mercado dado que la competencia sólo es posible en el marco de la interacción entre la oferta y la demanda que define el mercado.

El abuso de posición dominante se asocia con la idea de ejercicio del poder de mercado por parte de una empresa o grupo de empresas que tienen una posición monopólica o de liderazgo en un cierto mer-

20 Cases Pallarés L. Citado por Soriano García, ver cita No 27.

21 Richard A. Posner. El análisis Económico del Derecho, -traducción: E. Suárez-, Fondo de Cultura Económica, México, Capítulo IX «La Teoría del Monopolio», p.264. 
cado. Este concepto es tomado por la ex ley argentina de Defensa de la Competencia del artículo $86^{\circ}$ del Tratado de Roma de la Comunidad Europea de 1957. En este sentido se la interpreta normalmente con una noción más laxa que la del artículo $2^{\circ}$ de la "Ley Sherman" de los Estados Unidos de 1890, para la que es ilegal la "monopolización" de un mercado que en determinados casos puede asimilarse con la simple existencia de una posición de dominio.

En cambio en las legislaciones europeas y en esta ley argentina admiten como lícito que el mercado quede monopolizado por una sola empresa, se penan los abusos que dicha posición dominante puede originar.

La ley anterior tenía un mecanismo «represivo» de sanción de prácticas monopólicas, abuso de posición de dominio, acuerdo entre competidores, etc.; pero no impide la concentración de un gran poder de mercado, sino que sólo se preocupa de reprimir los abusos y disuadir prácticas distorsivas que puedan cometerse en el ejercicio de dicho poder. Estos conceptos económicos y tipos de infracción son generalmente tomados de la legislación comparada; lo que no es criticable; pero sí lo es sin embargo la escasa definición de los procedimientos, su remisión a los tipos penales y la falta de autonomía del órgano de aplicación, en este caso la Comisión Nacional de Defensa de la Competencia.

La diferencia más importante entre la ley vigente y la anterior, es que la Ley $\mathrm{N}^{\circ} 25.156$; no solo es de carácter «represivo", -al igual- la $N^{\circ} 22.262$; sino que además tiene un carácter "preventivo"; y de "Control posterior" de los monopolios.

La mayoría de los países del mundo que tienen una legislación específica en materia de defensa de la competencia les han incorporado mecanismos de previo control, de manera similar a lo planteado en la nueva ley argentina. El pionero en la materia fue Estados Unidos, que en 1914 sanciona la "Ley Clayton" en la que prevé el control previo de fusiones y concentraciones empresariales; sin embargo fue perfeccionada en 1976 por la "Ley Hart-Scott-Rodino" en la cual además se prevé la notificación previa de dichas concentraciones y fusiones a cargo de la División Antitrust del Departamento de Justicia y de la Comisión Federal de Comercio. Estos organismos a su vez elaboraron reglamentos y normas con los pasos a seguir en dicho procedimiento. La idea básica del procedimiento estadounidense de control previo es que las empresas que van a encarar una operación de adquisición o fusión cuya 
envergadura económica supere ciertos límites, deberán poner en conocimiento a las autoridades correspondientes encargadas de evitar los monopolios.

En la legislación Europea los procedimientos son muy similares al sistema americano en cuanto a sus procedimientos; pero distintos en su naturaleza jurídica. Se encuentra legislado a través del Reglamento No 4064/89 del Consejo de Europa, el que le confiere a la Comisión Europea no sólo facultades de investigación sino también que tenga poder de decisión respecto de las concentraciones y fusiones que tengan «dimensión comunitaria». Este poder abarca la posibilidad de aplicar sanciones tales como desautorizar una adquisición o fusión, separar empresas o activos agrupados y aplicar multas a las entidades involucradas. Las operaciones son definidas como de «dimensión comunitaria" por el volumen de negocio de las empresas involucradas y por el hecho de que más de un Estado miembro de la comunidad se encuentre significativamente afectado por la operación en cuestión.

En América Latina hay legislaciones que contemplan un sistema de control previo para las concentraciones y fusiones más importantes; tal el caso de Brasil-Ley No 8884 de 1994-; incluye un capítulo dedicado al control de actos y contratos, en el cual se sientan las bases de un sistema de notificación de las concentraciones y fusiones a cargo del Consejo Administrativo de Defensa Económica; también cuando las operaciones sobrepasan un determinado monto.

En México, la ley federal de competencia económica de 1992 contiene un capítulo dedicado a las concentraciones. El mismo dispone que la comisión federal de competencia tiene facultades de investigación y sanción de dichos actos y crea un procedimiento de control previo que es obligatorio para las operaciones que excedan determinado monto establecido en la ley.

En Canadá rige la «Federal Competition Act» de 1985 una legislación un tanto particular porque es una combinación de la legislación americana y la europea, ya que utiliza dos organismos de aplicación que se encargan respectivamente de evaluar las concentraciones y fusiones -Director de investigaciones y pesquisas-; y de decidir a cerca de su legalidad -Tribunal de Competencia-. Es distinta a las otras legislaciones también en cuanto a lo escueto de sus procedimientos y que no establece límites mínimos de notificación para las empresas intervinientes. 
Otro caso de separación parcial entre el órgano de investigación y el de aplicación de la ley de Competencia es en Sudáfrica, donde la primera de dichas funciones las realiza la Comisión de Competencia; y la segunda el Ministerio de Industria y Comercio. ${ }^{22}$

En cuanto al Mercosur ${ }^{23}$, en el Tratado de Asunción de 1991, ya se mencionaba que entre los países miembros la libre circulación de productos y servicios y factores de producción debe ser alcanzado en «adecuadas condiciones de competencia entre los Estados parte".

Sin embargo, consideramos que el instrumento de mayor relevancia; en relación a este tema son las reglas del "Protocolo de Defensa de la Competencia», -Decisión 18/96-, que constituye una herramienta imprescindible a fin de lograr asegurar las condiciones adecuadas de competencia que contribuyan a consolidar la integración al garantizar niveles similares de protección entre los Estados parte.

Es de importancia destacar que no existe en esta materia superposición de competencias entre la comunidad y dichos Estados parte. La legislación comunitaria se refiere a las prácticas anticompetitivas que afectan la competencia regional en el Mercosur. Sin embargo es competencia de cada Estado parte del Mercosur la «regulación de los actos practicados en su respectivo territorio por persona física o jurídica de derecho público o privado u otra entidad domiciliaria en él y cuyos efectos sobre la competencia a él restrinjan»-artículo $3^{\circ}-$.

De todos modos, queda aún mucho por hacer; solo Brasil y Argentina cuentan con una legislación de Defensa de la Competencia acorde a las legislaciones de los países más avanzados. Uruguay y Paraguay, todavía no han dictado ley alguna con estas características

\subsection{La nueva Ley antimonopolio ( $\left.\mathrm{N}^{\circ} 25.156\right)$}

La nueva ley antimonopolio fue aprobada el 25 de agosto y promulgada el 16 de septiembre de 1999; derogando a la Ley $\mathrm{N}^{\circ}$ 22.262. Las notas más sobresalientes de la misma en relación a la ley anterior están dada porque además de tener un carácter "represivo"; se incorporan

22 El Control Previo de las Concentraciones y Fusiones y la Defensa de la Competencia en los mercados, CNDC, Serie Documentos No 2, pp. 12-17.

23 Roberto Ampliar de Dromi. Op, cit. $\mathrm{N}^{\circ} 15$; pp, 46-53. 
mecanismos de carácter «preventivos»; los mismos tienden a evitar la monopolización o la excesiva concentración del poder de un mercado en pocas manos, a través de procedimientos de control de fusiones o adquisiciones de empresas, o de grandes contratos de colaboración empresaria.

El criterio que fundamenta estos mecanismos de carácter previo a la operación de concentración, no consiste en prohibir las fusiones u operaciones de concentración económica, ni someterlas en su totalidad a procedimientos de autorización, sino solamente se establece la presunción de que dichas operaciones pueden perjudicar el interés económico general, cuando se involucran empresas que detentan un gran poder de mercado y pretenden acrecentarlo.

Es un mecanismo preventivo excepcional, para aquellas operaciones que pueden poner en riesgo las condiciones estructurales de la competencia en los mercados; todas parten de la siguiente premisa: para acrecentar las participaciones de mercado hay que ganar clientes, pero no eliminar adversarios a través de su compra o anular la competencia acordando con competidores.

El análisis tanto jurídico como económico que llevarían a prohibir o condicionar una de estas operaciones sería entre otros factores, la dimensión del mercado, la cantidad de competidores, los avances tecnológicos, los desafíos de la importación, etc. Tampoco se pierden de vista los resultados esperados luego de la operación de concentración, y no siempre las concertaciones arrojan resultados negativos, puede ser beneficiosa para la competencia en términos de eficiencia económica, cuando por ejemplo cuestiones de escala de producción tornarían aconsejable la existencia de una o pocas grandes empresas, y no de muchas medianas o pequeñas que quizá no podrían amortizar inversiones o vender a precios competitivos. Se podrían citar muchos ejemplos; pero uno de ellos sería que en un país como el nuestro no se justificaría la presencia de múltiples empresas siderúrgicas o petroquímicas que requieren grandes inversiones y no tienen un mercado tan amplio como puede ser el norteamericano o el europeo y; si la multiplicidad de empresas de telefonía celular. ${ }^{24}$ En relación a este último caso bien vale como ejemplo el hecho de haberse permitido la participación de em-

24 Ernesto Cionfrini La Protección de los Mercados y la Competencia en la Constitución Nacional, -artículo en prensa- p. 15. 
presas ya establecidas, lo que estaba prohibido en normas previas, y se han otorgado enormes cantidades de frecuencias lo que ha redundado en el fortalecimiento de posición dominante en un mercado clave. Basta con señalar que en los Estados Unidos la aparición de las nuevas tecnologías celulares permitió la incorporación de cinco competidoras más al mercado, mientras que en la Argentina se admiten solo dos ${ }^{25}$.

Esto además de implicar un uso ineficiente de las frecuencias, que son un bien público limita a los consumidores en su derecho constitucional -artículo $42^{\circ}$ - de elegir su proveedor de servicios en un medio auténticamente competitivo.

Estos mecanismos de tipo "preventivos" surgen en su mayoría del análisis del Cápítulo III titulado «De las Concentraciones y Fusiones» -artículos $6^{\circ}$ al $16^{\circ}-$.

En el capítulo I titulado "De los Acuerdos y Prácticas prohibidas», artículo $2^{\circ}$, al igual que la ley anterior, establece las conductas prohibidas, pero en forma sumamente detallada en catorce incisos (de las letras «a» hasta «m») establecen cuales son aquellas prácticas; pero a pesar de esa minuciosidad, aclara la norma "[... las siguientes conductas entre otras [...]", de lo cual surge que es una norma meramente enunciativa, y que aún pude haber más conductas pasibles de ser consideradas "monopólicas» por el Tribunal de Defensa de la Competencia, en este caso la autoridad competente.

En el Capítulo «De la posición Dominante»; se define a los efectos de la presente ley qué se entiende por posición dominante del mercado, artículo $4^{\circ}$; pero el concepto no difiere de la ley anterior, pues la ley vigente es muy similar.

Otra nota distintiva, y a mi juicio beneficiosa es que la ley crea el Tribunal Nacional de Defensa de la Competencia, Capítulo IV «Autoridad de aplicación" -artículos $17^{\circ}$ al $24^{\circ}$-; el que tendrá carácter autárquico y podrá intervenir por denuncias y también de oficio ante prácticas antimonopólicas o prohibidas.

Estará integrado por siete miembros que serán designados por el poder ejecutivo previo concurso público de antecedentes y oposición, y durarán en el ejercicio de sus cargos por seis años. «Los mismos serán designados por el Poder Ejecutivo Nacional, previo concurso público

25 Información de La Nación, Buenos Aires 25 de agosto de 1999, p. 16, «Información General». 
de antecedentes y oposición ante un jurado integrado por el Procurador del Tesoro de la nación, el Secretario de Industria, Comercio y Minería del Ministerio de Economía, Obras y Servicios de la Nación, los presidentes de las Comisiones de Comercio de ambas Cámaras del Poder Legislativo de la Nación, el presidente de la Cámara Nacional de Apelaciones en lo Comercial y los presidentes de la Academia Nacional de Derecho y de la Academia Nacional de Ciencias Económicas».

Es importante mencionar que si bien se establece claramente el órgano de aplicación del régimen de defensa de la competencia, en nuestro país existen también entes reguladores ${ }^{26}$ para cada uno de los servicios públicos; los que tienen entre sus obligaciones fundamentales el deber de verificar que los servicios públicos se presten en las condiciones pactadas de calidad y seguridad. Asimismo, deben asegurar que las empresas prestatarias de servicios realicen las inversiones comprometidas, mantengan las tarifas pactadas, atiendan los reclamos de los usuarios y protejan al medio ambiente.

Entre sus principales funciones se encuentra la de supervisar y controlar el efectivo cumplimiento de las obligaciones asumidas por quienes han de brindar los servicios públicos; entre ellos el control relativo a la competencia dentro de cada sector. Tal es el caso del artículo $19^{\circ}$ de la Ley $\mathrm{N}^{\circ} 24.065$, la que establece el marco regulatorio de la energía eléctrica; estipula, "Los generadores, transportistas y distribuidores no podrán realizar actos que impliquen competencia desleal, ni abuso de una posición dominante del mercado [...]», remitiendo a la ley nacional de Defensa de la Competencia.

Se crea asimismo el Registro Nacional de Defensa de la Competencia -artículo $23^{\circ}$-, donde deberán inscribirse las operaciones de concentración económica prevista en el Capítulo III y las resoluciones definitivas dictadas por el Tribunal, el registro será público.

El Tribunal deberá organizar dicho registro y; es una de sus principales funciones la de autorizar operaciones de gran envergadura; lo que no debemos descartar es la posibilidad de convertirse en un arma de doble filo; puesto que en los Estados Unidos y en Europa existe el requisito de autorización previa cuando se dan determinadas condiciones de contratación, pero ese control está siempre sujeto a plazos cor-

26 Ente Nacional Regulador de la Electricidad -ENRE-; Ente Nacional Regulador del Gas -ENARGAS- 
tos -en nuestra ley se prevén noventa días-, y a un régimen de aprobación prácticamente automático.

Para que un sistema de este tipo funcione se requiere fundamentalmente transparencia por parte de los órganos del Estado. En países con un alto grado de corrupción, burocráticos y con traumas ideológicos, la exigencia de aprobación anterior o posterior puede transformarse en una valla infranqueable para la adquisición o fusión de empresas. Lamentablemente Argentina está entre ese grupo de países.

Viendo el lado positivo; aquí se advierte nuevamente el carácter "preventivo" de la norma. Además, creo que deberíamos apuntar que se prevé un mayor control, al haber una autoridad de aplicación determinada, con carácter autárquico tal como surge del artículo $17^{\circ}$ y con amplias facultades establecidas en dieciocho incisos del artículo $20^{\circ}$; tales como vetar fusiones de empresas y bancos, verificar el abuso de posición dominante, promover acciones ante la justicia y dictar su reglamento interno; ello además de imponer las sanciones previstas en el proyecto.

Las sanciones están previstas en el Capítulo VII -artículos $46^{\circ}$ a $51^{\circ}$ - y se refiere a multas que oscilarán entre $\$ 10.000$ y $\$ 150.000 .000$ para quienes realicen las prácticas prohibidas; las que se elevarán a \$1.000.000 diarios cuando las empresas no cumplan con la obligación de notificar al Tribunal de toda fusión de empresa que supere el 25\% del mercado relevante; o cuando el volumen del negocio supere los $\$ 200$ millones en el país; o $\$ 250$ millones en el nivel mundial - artículos $8^{\circ}, 35^{\circ}$ y $36^{\circ}-$.

Uno de los temas del proyecto de la presente ley que suscitó mayores controversias fue la modificación que introdujo la Cámara Alta al original enviado por la Cámara de Diputados de la supresión del artículo $58^{\circ}$, en el que se establecía que la presente ley no será aplicable a las empresas periodísticas; modificación finalmente acatada por la Cámara Baja; puesto que el proyecto fue aprobado tal como lo enviara el Senado sin modificaciones. Consideramos que en nada peligra la libertad de prensa -argumento sostenido por quienes pensaron correcta la incorporación de dicho artículo-; puesto que tan cara libertad, esencial en un sistema republicano goza de suficiente protección constitucional en los artículos $14^{\circ}$ y $32^{\circ}$; y en los tratados internacionales incorporados a la Constitución nacional. 
Esta nueva ley traería aparejado importantes beneficios, sobre todo en mérito al control y porque con esta ley ha salido a la luz la conveniencia del control previo de las concentraciones y fusiones por parte de la autoridad competente.

En los países más desarrollados rige desde hace varias décadas leyes antimonopolios; porque las consideran fundamental en el desarrollo de su economía; a modo de ejemplo el Departamento de Justicia de los Estados Unidos multó recientemente a los laboratorios farmacéuticos Roche y Basf con US\$ 725 millones, por concertar los precios de las vitaminas A, B2, B5, C, E, y betacaróteno. Según pudo comprobarse, ambas empresas se reunían cada mes para repartirse el mercado. Fue la multa más alta aplicada en los EE.UU. por prácticas monopólicas hasta la fecha. ${ }^{27}$

La Ley No 22.262 no preveía un esquema explícito de control previo o posterior de las concentraciones y fusiones empresarias, la ley parece pensada para resarcir daños ocurridos efectivamente y no para solucionar problemas estructurales de mercado; lo que ha hecho que prácticamente no hayan existido procesos relacionados con las concentraciones y fusiones, ni tampoco resoluciones.

La apertura económica de Argentina en los últimos años y la desregulación de los mercados que muy lentamente ha comenzado, hace que se torne una necesidad imperiosa contar con una legislación antimonopólica similar a la de los países más civilizados del mundo. Por otra parte, si uno de los fundamentos de las privatizaciones es evitar los monopolios del Gobierno, que se han demostrado perversos, es necesario el reaseguro de que no se produzcan los mismos monopolios pero en manos privadas.

Quizá es una prueba de ello que el tratamiento de la nueva ley, se vio acelerado con la compra de la empresa «YPF» por parte de la empresa petrolera española «Repsol». Esta operación, ha sido sin duda la de mayor envergadura en su sector en la historia argentina, ha sido muy cuestionada por diversos sectores que temen un monopolio extranjero en un mercado tan sensible como el de los combustibles. Si bien las leyes no son retroactivas y no sería aplicable a dicha operación; Repsol no quedará exenta de controles de acuerdo a la normativa de la presente ley; y el Tribunal podrá imponer condiciones para evitar los

27 La Nación, Buenos Aires 20 de junio de 1999, p. 7, "Información General». 
aspectos distorsionadores de la competencia. Incluso como el Tribunal tiene facultad de intervención ante la justicia, podrá solicitar a un juez que la empresa sea desconcentrada o dividida si se prueba que asume una posición dominante en el mercado; de acuerdo al artículo $8^{\circ}$ de la misma. En su momento. el Ministerio de Economía se anticipó a la ley y ha comunicado a Repsol que, tras la toma de YPF, deberá cumplimentar un programa de venta de activos destinados a acotar su participación de mercado en la industria petrolera nacional. ${ }^{28}$

Cabe mencionar que YPF ya había sido sancionada, por conductas de abuso de posición dominante. El 11 de agosto de 1997, se había iniciado una causa, "YPF, S.A s/ Multa», ante la Comisión Nacional de Defensa de la Competencia, a través de una investigación de oficio, con fundamento en el artículo $18^{\circ}$ de la entonces Ley vigente $\mathrm{N}^{\circ} 22.262$. La sanción surge de la Resolución No 189 (BO, 25/3/99); la Secretaría de Industria, Comercio y Minería aplicaba una sanción por considerar comprobadas las conductas investigadas en el marco de la anterior ley de Defensa de la Competencia. La sanción consistió en primer lugar, en ordenar el cese inmediato de las conductas de posición dominante; en segundo lugar en la imposición de una serie de obligaciones, tales como omitir la discriminación de precios, eliminar los contratos de exportación vigentes, etc.; y, en tercer lugar, se impuso en el caso la multa máxima permitida por la ley. ${ }^{29}$

El reciente dictamen de la Secretaría de Defensa de la Competencia por el que se recomienda al Ente Nacional de Regulación Eléctrica, que es el grupo español Endesa, se desprenda de sus acciones en alguna de las dos distribuidoras eléctricas -Edenor y Edesur-es un público y saludable llamado de atención, en relación al tema que nos ocupa; dado el serio problema planteado en ese orden en el sector energético argentino.

Tal como ocurrió con el tema de YPF; actualmente en dicho sector parece claramente que se va configurando una deformación de mercado. Si bien es generalmente aceptado que la privatización del sector de la electricidad ha sido una de las más transparentes, eso no es óbice a que desde hace un tiempo se viene produciendo una concentración de distintas actividades en clara violación al marco regulatorio de la misma, o sea a la Ley $\mathrm{N}^{\circ} 24.065$, según el cual quienes desarrollen alguna

28 La Nación, Buenos Aires 24 de junio de 1999.

29 Roberto Ampliar de Dromi, Op. cit., pp. 259-265. 
actividad de la industria eléctrica (generación, transportación o distribución), no podrán tomar a su cargo cualquiera de las otras dos.

Si bien el tema tratado por la Secretaría de Defensa de la Competencia hace referencia a Ednor y Edesur: cabe destacar que Endesa -de acuerdo con las informaciones obrantes en el ENRE- es controlante o importante accionista, tanto en centrales térmicas e hidroeléctricas de generación, como en actividad de transporte.

Esta situación nos hace reflexionar en sentido del riesgo que entraña para el país que un mercado competitivo, como el desarrollado en este aspecto -generación de electricidad-, y que ha permitido lograr tarifas competitivas para las industrias nacionales, deje de serlo por estas situaciones claramente violatorias de la ley; y la gravedad, que justamente significa el hecho de violar esta ley. ${ }^{30}$

En aquellos países en los que la libertad económica ha permitido el desarrollo de mercados se han preocupado por mantener su transparencia, y lo han logrado a través de entes reguladores, técnicamente capacitados; y sobre todo independientes, que han hecho cumplir en forma permanente la legislación vigente, llevando adelante todo tipo de acciones orientadas a ese fin.

\section{Conclusiones}

En la última década se ha producido una reorganización de la economía argentina; la que sin duda trajo aparejado grandes cambios; cuyos ejes han sido la estabilidad de los precios, a través de la convertibilidad; la desregulación de los mercados, la apertura económica externa; y las privatizaciones.

En este marco, aparece el Estado no como dueño de los servicios públicos; sino en su papel de "Estado Regulador»; redefiniendo así la función del Estado; que no participa directamente en la producción de bienes y servicios sino que los ha transferido a manos privadas.

Como consecuencia de las razones expuestas, las políticas de competencia adquirieron una importancia preponderante; a punto tal que la misma reforma constitucional de 1994; acompaña este proceso desde su regulación específica en el segundo párrafo del artículo $42^{\circ}$.

30 La Nación, nota Editorial «Monopolios que no se ven», 16 de Junio de 2000. 
En este contexto, se sancionó la Ley antimonopolio $N^{\circ}$ 25.156; que es fundamental en esta etapa de nuestra realidad económica; entendemos claramente que se trata de una ley reglamentaria del derecho establecido en la mencionada norma constitucional.

De modo que la nueva ley vendría a suplir una necesidad que ha sido consecuencia de los cambios operados en nuestro país en el ámbito económico, cambios que por otra parte no resultan efectivos si no va acompañado de este tipo de leyes.

Si bien es cierto que recién estamos comenzando a recorrer este camino, y ello implica que se den situaciones de no aplicación o de violación a la ley; tal como señalamos en párrafos anteriores; no es menos cierto que tenemos grandes posibilidades de ir perfeccionando día a día; y lograr lo que han alcanzado otros países que vienen trabajando en el tema varias décadas antes que Argentina.

En aquellos países en los que la libertad económica ha permitido el desarrollo de mercados se han preocupado por mantener su transparencia, y lo han logrado a través de entes reguladores, técnicamente capacitados; y sobre todo independientes, que han hecho cumplir en forma permanente la legislación vigente, llevando adelante todo tipo de acciones orientadas a ese fin.

«Privatización, debe significar competencia entre empresas por el derecho a prestar el servicio acompañada de un importante control gubernamental; generalmente requiere de desregulación, para evitar estas concentraciones de mercado; y la desregulación debe requerir de mayores y serios esfuerzos de parte de los gobiernos para aplicar $y$ hacer efectivas las leyes antimonopólicas». ${ }^{31}$

31 Susan Rose Ackerman. Desregulación y Privatizaciones en los Estados Unidos. Críticas desde un enfoque progresista, Revista Jurídica de la Universidad de Palermo, Buenos Aires, abril de 1996, p. 45. 